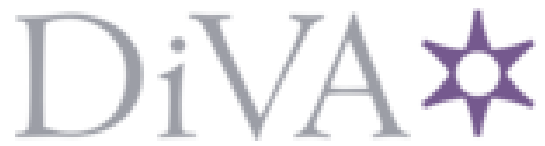

http://www.diva-portal.org

Preprint

This is the submitted version of a paper published in IEEE transactions on industrial electronics (1982. Print).

Citation for the original published paper (version of record):

Millinger, J., Bacco, G., Manzolini, V., Wallmark, O., Bianchi, N. (2019)

Design and Evaluation of a Short-Circuit Rotor-Ring for Enhanced Self-Sensing

Capability in a Slotless PM Motor

IEEE transactions on industrial electronics (1982. Print)

https://doi.org/10.1109/TIE.2019.2921266

Access to the published version may require subscription.

N.B. When citing this work, cite the original published paper.

Permanent link to this version:

http://urn.kb.se/resolve?urn=urn:nbn:se:kth:diva-253269 


\title{
Design and Evaluation of a Short-Circuit Rotor-Ring for Enhanced Self-Sensing Capability in a Slotless PM Motor
}

\author{
Jonas Millinger, Member, IEEE, Giacomo Bacco, Member, IEEE, Virginia Manzolini, Member, IEEE, Oskar \\ Wallmark, Senior Member, IEEE, and Nicola Bianchi, Fellow, IEEE
}

\begin{abstract}
This paper deals with the design and evaluation of a short-circuit rotor-ring for enhanced self-sensing capability in a 2-pole slotless permanent-magnet motor. High-frequency rotor anisotropy is enabled by adding a short-circuited rotor-ring. Optimal ring-dimensions are determined by parametric numerical studies. An effective high-frequency saliency of up to $\mathbf{1 . 8}$ is demonstrated. The steady-state estimation error is within $\pm 2^{\circ}$, practically unaffected by current level (in contrast to slotted self-sensing electrical machinery) due to the large effective air-gap. The proposed observer performs properly also during dynamic load changes. Fall-times from 3000 to $0 \mathrm{rpm}$ in less than $50 \mathrm{~ms}$ with negligible overshoot are demonstrated. Also parasitic effects such as power losses, heating and torque ripple are analyzed.
\end{abstract}

Index Terms-Rotor position estimation, saliency-based sensorless control, self-sensing, slotless permanentmagnet motor.

\section{INTRODUCTION}

$\mathbf{S}$ LOTLESS permanent magnet motors are preferred within power tools, machine spindles, turbine generators, compressors and turbo-machinery due to their high rotational speed [1]-[4], subsequently enabling high power density. Accurate control of such motors, using a power electronic inverter, requires knowledge of the rotor position and speed [5]. This is typically achieved by using a mechanical position sensor (see Fig. 1). An alternative is to adopt a sensorless control algorithm [6]-[9], so as to eliminate the position sensor and subsequently reduce cost, increase robustness and reliability, and reduce size [10].

While back-EMF based methods [11]-[14] provide sufficient control capability in the medium to high speed range, the low speed range requires active position detection methods [15], [16]. A prerequisite for low-speed self-sensing capability using signal injection is an adequate level of magnetic

Manuscript received November 19, 2018; revised February 15, 2019 and April 17, 2019; accepted May 20, 2019. This work was supported in part by Atlas Copco Industrial Technique AB, Stockholm, Sweden. J. Millinger and O. Wallmark are with the Division of Electric Power and Energy Systems, KTH Royal Institute of Technology, Stockholm, Sweden (e-mail: jonasmil@kth.se; owa@kth.se). G. Bacco, V. Manzolini and $\mathrm{N}$. Bianchi are with the Department of Industrial Engineering, University of Padova, Padova 35131, Italy (e-mail: giacomo.bacco@phd.unipd.it; virginia.manzolini@studenti.unipd.it; nicola.bianchi@unipd.it). (corresponding author: Jonas Millinger; phone: +46702919187; e-mail: jonasmil@kth.se) anisotropy [8], [17]. Furthermore, the $180^{\circ}$ ambiguity of estimation for injection-based methods also requires an algorithm for initial polarity detection [18]-[20].

Many motor types, such as the interior and inset PM motor, have a natural magnetic anisotropy due to rotor structure [21][23] which enables usage of active position detection methods. Unfortunately, Surface-mounted PM (SPM) motors such as the machine type under investigation, exhibit no magnetic anisotropy based on structure. Instead, such motors can utilize the position dependent inductance due to core saturation and anisotropic permeability of permanent magnets. However, this effect is very limited in slotless motors (typically less than $1 \%$ ) compared to slotted ones [24], [25], resulting in a low signal-to-noise ratio. It can be improved by oversampling the phase currents during their transient response to voltage pulses over several PWM periods [26], enabling position estimation in slotless PM motors within $\pm 30^{\circ}$ for rotor speeds below $200 \mathrm{rpm}$ [25]. However, high-dynamic control of slotless PM motors requires significantly improved position estimation capability. Another way to enhance magnetic anisotropy in slotted SPM motors is to utilize a rotor winding [27]-[30], enabling an asymmetric high-frequency signal response. The method not only improves anisotropy but also the sensitivity to saturation and $d$ and $q$-axis cross-coupling [28], [31] at the expense of additional rotor losses [32]. Compared to conventional slotted machinery, the slotless motor type has significant advantages in terms of negligible amount of space harmonics [33], [34] and very limited saturation effects [24]. Therefore, this paper presents the previously unprecedented analysis of a short-circuit rotor-ring design methodology for a 2-pole slotless PM motor, enabling accurate self-sensing control capability in the full speed-range.

The investigated machine and the application is presented in Section II. The ring design is made in Section III.

The motor control scheme is described in Section IV. An estimation error analysis, accompanied by the proposed compensation method, is presented in Section V. The power losses and resulting thermal influence, as well as the torque ripple due to the rotor-ring are considered in Section VI. Finally, conclusions are drawn in Section VII.

\section{INVESTIGATED MOTOR}

The investigated motor, sketched in Fig. 1 and Fig. 2a, belongs to an industrial nutrunner. Deep analysis of such 


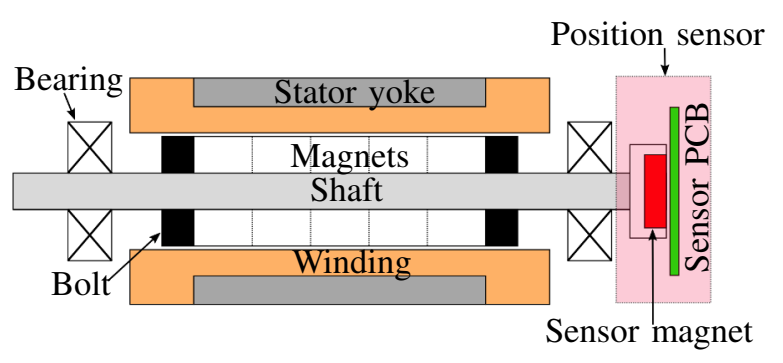

Fig. 1. Motor module radial cross-section.

TABLE I

MOTOR DATA

\begin{tabular}{lll}
\hline \hline Quantity & Symbol & Value \\
\hline Peak torque & $T_{\max }$ & $1.15 \mathrm{Nm}$ \\
Maximum speed & $n_{\max }$ & $36 \mathrm{krpm}$ \\
Peak phase current & $I_{\max }$ & $20 \mathrm{~A}$ \\
Nominal DC-bus voltage & $U_{\mathrm{DC}}$ & $325 \mathrm{~V}$ \\
Motor active length & $L_{a}$ & $64.5 \mathrm{~mm}$ \\
Stator outer radius & $r_{\mathrm{lam}}$ & $15.5 \mathrm{~mm}$ \\
Rotor radius & $r_{r}$ & $7.5 \mathrm{~mm}$ \\
Air-gap length & $\delta$ & $0.5 \mathrm{~mm}$ \\
Magnet remanent flux density & $B_{r}$ & $1.3 \mathrm{~T}$ \\
\hline \hline
\end{tabular}

machinery can be found in for example [1]-[4], [33], [34]. The absence of slots eliminates cogging torque and provides a practically linear current versus torque relationship [24], subsequently improving position control capability. The rotor comprises a solid shaft carrying axially segmented ring $\mathrm{NdFeB}$-magnets with parallel magnetization. The stator consists of an overlapping winding inside a cylindrical stator yoke of axially laminated stator steel.

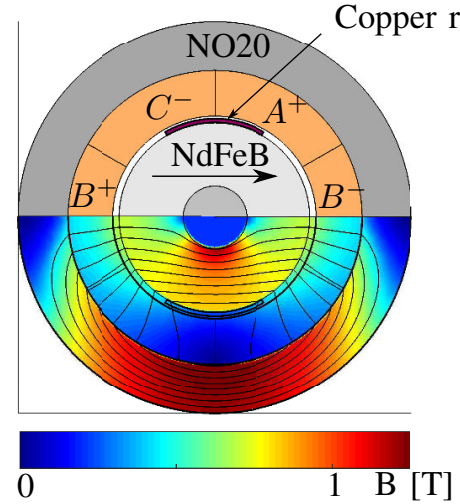

a)

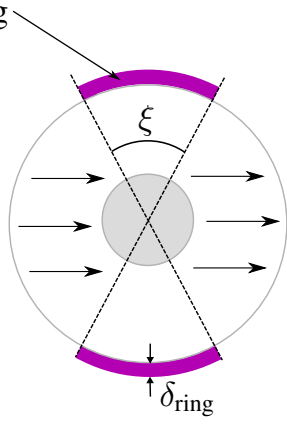

b)
Fig. 2. Axial cross-section of a) The slotless motor $\left(i_{a, b, c}=0\right.$ A, i.e., field lines only due to rotor PMs); b) The proposed rotor structure.

Original motor data (maintained throughout the study) are provided in Table I. The proposed rotor-ring is illustrated in Fig. 2b. The typical drive cycle is shown in Fig. 3 characterized by the high-speed rundown at negligible load, followed by a fast braking and a low-speed tightening until the target torque. From a sensorless control point of view, the challenges are the

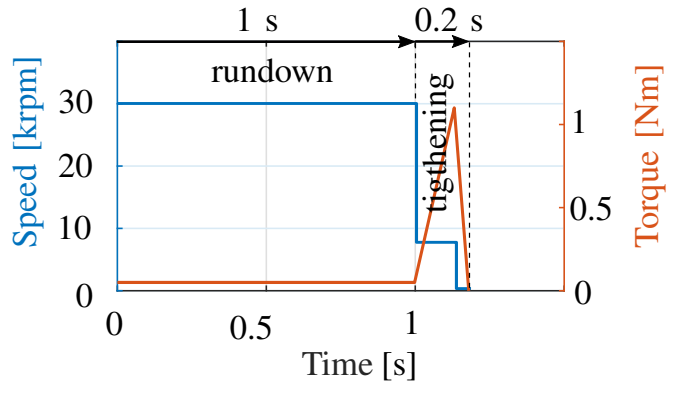

Fig. 3. Typical load profile of an electric motor for handheld nutrunners: a) rundown $\left(T_{\text {rundown }} \approx 1 \mathrm{~s}\right)$; b) tightening $\left(T_{\text {tight }} \approx 0.2 s\right)$.

low speed operation at load and the fast braking capability, requiring high dynamic speed control.

The small-signal flux density distribution for d-axis AC current at different levels of q-axis DC-current have been simulated for $\left\{\xi=60^{\circ}, \delta_{\text {ring }}=0.3 \mathrm{~mm}\right\}$ in Fig. 4 using the frozen permeability method (i.e., the flux density distribution from permanent magnets and the fundamental q-axis DC-current determines the small-signal AC frozen permeability map. As can be seen in Fig. 4a-b, the ring has a negligible effect on $q$-axis AC flux, but significantly counter-acts $d$-axis AC flux. This anisotropic reaction yields an effective AC rotor saliency which can be utilized for accurate rotor position detection. Fig. 4c shows the small signal flux pattern under heavily loaded conditions $\left(i_{q}=60 \mathrm{~A}\right)$. While no significant reduction of the small-signal AC flux densities can be observed, an increased level of $d$ and $q$-axis cross-coupling can be seen (due to core saturation), resulting in an estimation error. The error angle $\theta_{\text {error }}$ for $i_{d}=1 \mathrm{~A}$ has been quantified for a wide range of $i_{q}$ using:

$$
\theta_{\text {error }}=\arctan \left(\frac{\Psi_{q}}{\Psi_{d}}\right)
$$

where $\Psi_{d}$ and $\Psi_{q}$ are the small-signal $d$ and $q$-axis flux linkages obtained by 2D FEA at $3125 \mathrm{~Hz}$. The results are presented in Fig. 5, showing only $0.7^{\circ}$ estimation error at $i_{q}=I_{\max }$ which can be explained by the large relative airgap of the investigated machine. At 3 times the max current $\left(i_{q}=60 \mathrm{~A}\right)$, the error is around $6.3^{\circ}$. Using Eq. (2), the influence of saturation on saliency was investigated; at max current $\left(i_{q}=20 \mathrm{~A}\right)$ the saliency decreased with less than $0.2 \%$ compared to the no-load case. At three times the maxium current $\left(i_{q}=60 \mathrm{~A}\right)$ the saliency decreased with less than $4 \%$.

\section{RING DESIGN}

In this section, the ring dimensions are determined by smallsignal harmonic finite element analysis, deploying the frozen permeability method (i.e., the flux density distribution due to permanent magnets determines the frozen permeability map). The goal is to maximize the saliency, defined as:

$$
\frac{Z_{q}(\omega)}{Z_{d}(\omega)}=\frac{\left|Z_{\mathrm{q}, \text { active }}(\omega)+Z_{\mathrm{ew}}\right|}{\left|Z_{\mathrm{d}, \text { active }}(\omega)+Z_{\mathrm{ew}}\right|}
$$

where $Z_{\mathrm{d} \text {,active }}$ and $Z_{\mathrm{q} \text {,active }}$ are the $d$ and $q$-axis active length impedances, obtained by FEA. $Z_{\mathrm{ew}}=R_{\mathrm{ew}}+j \omega L_{\mathrm{ew}}$ is the 

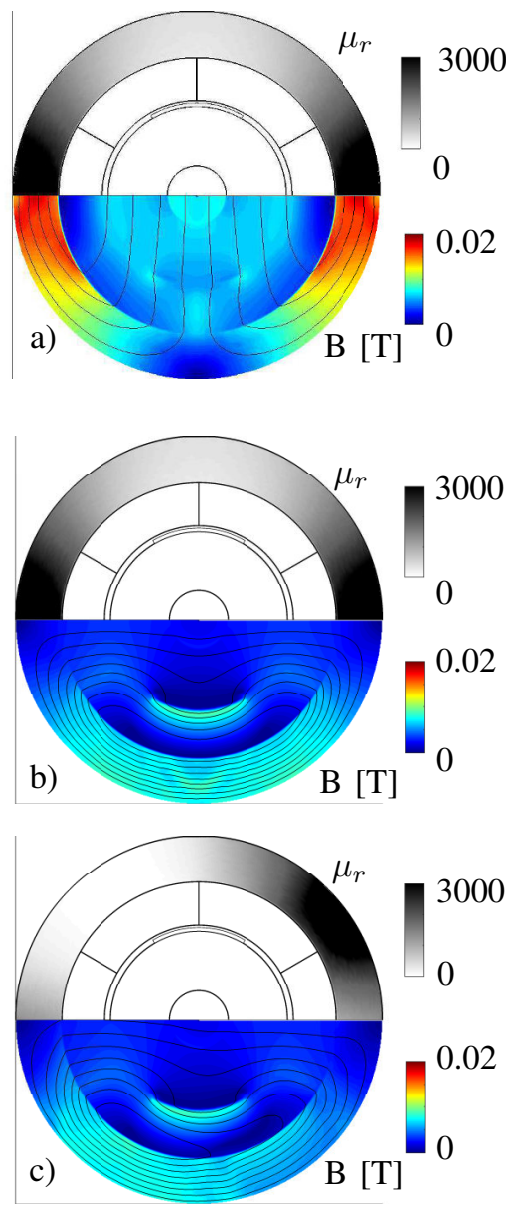

Fig. 4. Small-signal flux density distribution at $3125 \mathrm{~Hz}$ using the frozen permeability method for a) $\left\{i_{d, q}(\mathrm{DC})=0 \mathrm{~A}, i_{q}(\mathrm{AC})=1 \mathrm{~A}\right\}$; b) $\left.\left\{i_{d, q}(\mathrm{DC})=0 \mathrm{~A}, i_{d}(\mathrm{AC})=1 \mathrm{~A}\right\} ; \mathrm{c}\right)\left\{i_{q}(\mathrm{DC})=60 \mathrm{~A}, i_{d}(\mathrm{AC})=1 \mathrm{~A}\right\}$.

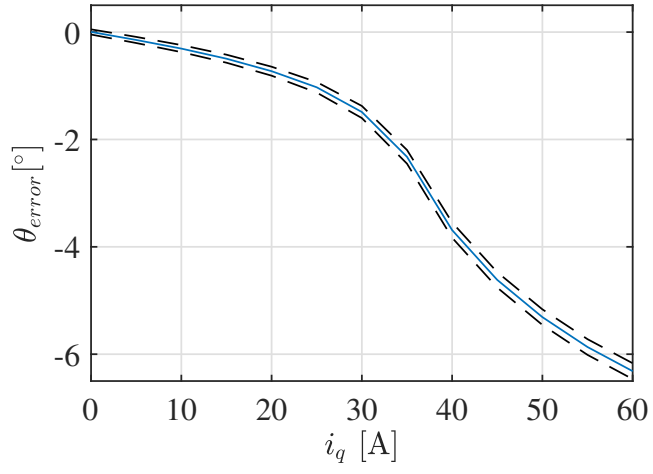

Fig. 5. Influence of q-axis current on angular error $\left(i_{d}=0 \mathrm{~A}\right)$. Solid line shows the mean error while dashed lines show max and minimum values obtained over one mechanical revolution.

analytically computed end-winding impedance [1]. Two parametric studies have been carried out at no-load (i.e., $i_{q}=0$ ):

- Influence of ring angular width $\xi$ (see Fig. 6)

- Influence of ring thickness $\delta_{\text {ring }}$ (see Fig. 7)

Within the investigated frequency range, results suggest an angular width not exceeding $60^{\circ}$, while no upper limitation can be seen from thickness point of view.

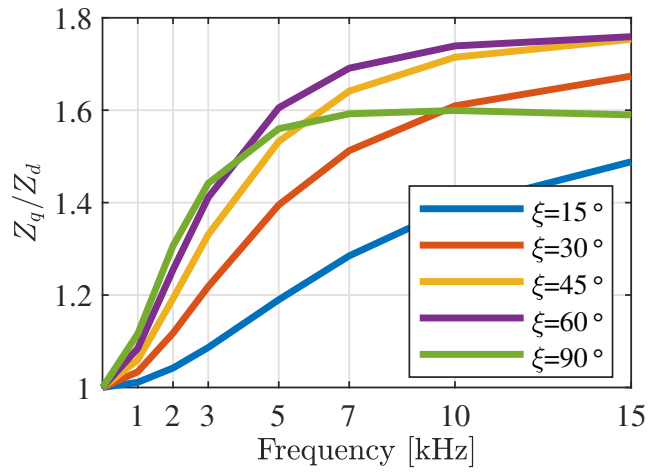

Fig. 6. Influence of ring arc angle $\xi$ on saliency (for $\delta_{\text {ring }}=0.3 \mathrm{~mm}$ ).

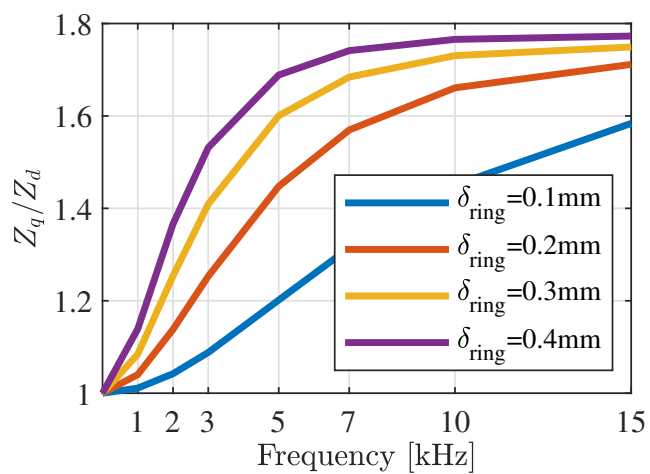

Fig. 7. Influence of ring thickness $\delta_{\text {ring }}$ on saliency (for $\xi=60^{\circ}$ ).

\section{A. Semi-analytical approach}

As demonstrated in [29], the $d$ and $q$-axis active part impedances $Z_{\mathrm{d} \text {,active }}$ and $Z_{\mathrm{q} \text {,active }}$ can be expressed analytically:

$$
Z_{\mathrm{x}, \mathrm{active}}=\underbrace{\left[R_{a}+\frac{\omega^{2} R_{\mathrm{rx}} M_{\mathrm{rx}}^{2}}{R_{\mathrm{rx}}^{2}+\omega^{2} L_{\mathrm{rx}}^{2}}\right]}_{R_{\mathrm{eq}, \mathrm{x}}}+j \omega \underbrace{\left[L_{a}-\frac{\omega^{2} L_{\mathrm{rx}} M_{\mathrm{rx}}^{2}}{R_{\mathrm{rx}}^{2}+\omega^{2} L_{\mathrm{rx}}^{2}}\right]}_{L_{\mathrm{eq}, \mathrm{x}}}
$$

where $R_{a}$ and $L_{a}$ are the active length phase-to-phase resistance and inductance, respectively. $R_{r x}$ represents the ring resistance and $L_{\mathrm{rx}}$ the ring inductance. $M_{\mathrm{rx}}$ is the ring to stator winding mutual coupling obtained using the power-invariant Clarke transformation. The deployed parameter values are summarized in Table II. The phase-to-phase quantities have been measured, while ring quantities were extracted from FEA, assuming the ring current paths shown in Fig. 8.
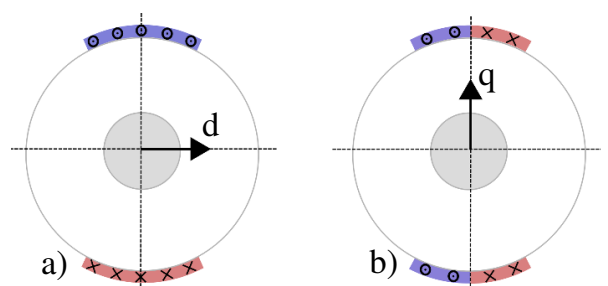

Fig. 8. Assumed ring current paths for calculation of: a) $d$-axis; b) $q$-axis parameters. 
TABLE II

MOTOR PARAMETERS

\begin{tabular}{lll}
\hline \hline Quantity & Symbol & Value \\
\hline Active length phase-to-phase resistance & $R_{\mathrm{a}}$ & $1.55 \Omega$ \\
End-winding phase-to-phase resistance & $R_{\mathrm{ew}}$ & $0.4 \Omega$ \\
Active phase-to-phase inductance & $L_{\mathrm{a}}$ & $0.95 \mathrm{mH}$ \\
End-winding phase-to-phase inductance & $L_{\mathrm{ew}}$ & $0.26 \mathrm{mH}$ \\
Ring $d$-axis mutual inductance & $M_{\mathrm{rd}}$ & $8.81 \mu \mathrm{H}$ \\
Ring $q$-axis mutual inductance & $M_{\mathrm{rq}}$ & $2.26 \mu \mathrm{H}$ \\
Ring $d$-axis resistance & $R_{\mathrm{rd}}$ & $1.7 \mathrm{~m} \Omega$ \\
Ring $q$-axis resistance & $R_{\mathrm{rq}}$ & $3.4 \mathrm{~m} \Omega$ \\
Ring $d$-axis inductance & $L_{\mathrm{rd}}$ & $118.6 \mathrm{nH}$ \\
Ring $q$-axis inductance & $L_{\mathrm{rq}}$ & $58.2 \mathrm{nH}$ \\
\hline \hline
\end{tabular}

\section{B. Ring assembly considerations}

The glued joints between the rotor and copper sleeves have to withstand the centrifugal forces due to rotation $\sigma_{\text {centrifugal }}$ and shear stress due to thermal expansion $\sigma_{\text {shear }}$ according to:

$$
\sigma_{\text {centrifugal }}=\frac{m \omega^{2} r_{r}}{A_{\text {contact }}}, \quad \sigma_{\text {shear }}=\frac{E_{\mathrm{Cu}} A_{\text {cross }} \alpha_{\text {diff }} \Delta T}{A_{\text {contact }}}
$$

where $m$ is the sleeve mass, $\omega$ the rotor angular speed and $A_{\text {contact }}$ is the contact area between the rotor and sleeve. $E_{\mathrm{Cu}}$ is the Young's modulus of copper and $A_{\text {cross }}$ the axial crosssectional area. $\alpha_{\text {diff }}=\alpha_{\mathrm{Cu}}-\alpha_{\mathrm{NdFeB}}$ is the differential coefficient of thermal expansion and $\Delta T$ the temperature difference. The centrifugal force at $36 \mathrm{krpm}$ and shear stress at $\Delta T=150 \mathrm{~K}$ result in $287 \mathrm{kPa}$ tensile stress and $360 \mathrm{kPa}$ shear stress in the glued joint. While both of these values are relatively low, the thermal cycling and class $\mathrm{H}$ temperature requirements limit the choice of adhesives to mainly special types of urethane modified acrylic compounds and epoxies [35].

\section{Prototype evaluation}

A ringed-pole rotor [28] was built using commercially available copper sheet with $0.3 \mathrm{~mm}$ thickness (nominal composition $99.9 \%$ copper and $0.042 \%$ phosphour). Two pieces of $100 \mathrm{~mm}$ long strips (see Fig. 9a), each spanning $\xi=60^{\circ}$ of the rotor surface, were symmetrically assembled around the $d$-axis using glue. The copper sheets were connected in each end using two parallel conductors of $1.5 \mathrm{~mm}^{2}$ crosssectional area, as shown in Fig. 9b. The prototype saliency was evaluated by connection to a linear amplifier cascaded with a signal generator. The $d$ and $q$-axis impedances were computed in the frequency range $1-15 \mathrm{kHz}$, deploying Fourier analysis. A LEM PR30 with $100 \mathrm{kHz}$ bandwidth was used for the current measurement, while voltage was acquired with a SI-9002 differential probe (25 MHz bandwidth). The experimental results are compared to simulated and semianalytically computed values in Fig. 10, showing satisfactory agreement.

\section{SENSORLESS MOTOR CONTROL}

The motor was connected to a MACNO TDE OPD F32A three-phase inverter. The DC-bus voltage was reduced to $42 \mathrm{~V}$ (using a transformer) in order to protect the hardware from over-currents, yet enabling the intended low-speed tests. Inverter data can be found in Table III. The manufactured

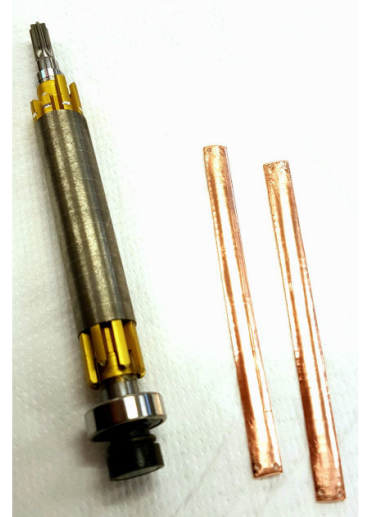

a)

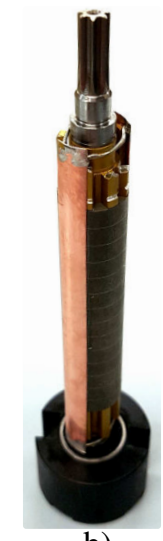

b)
Fig. 9. Rotor prototype a) Before assembly; b) Fully assembled rotor.
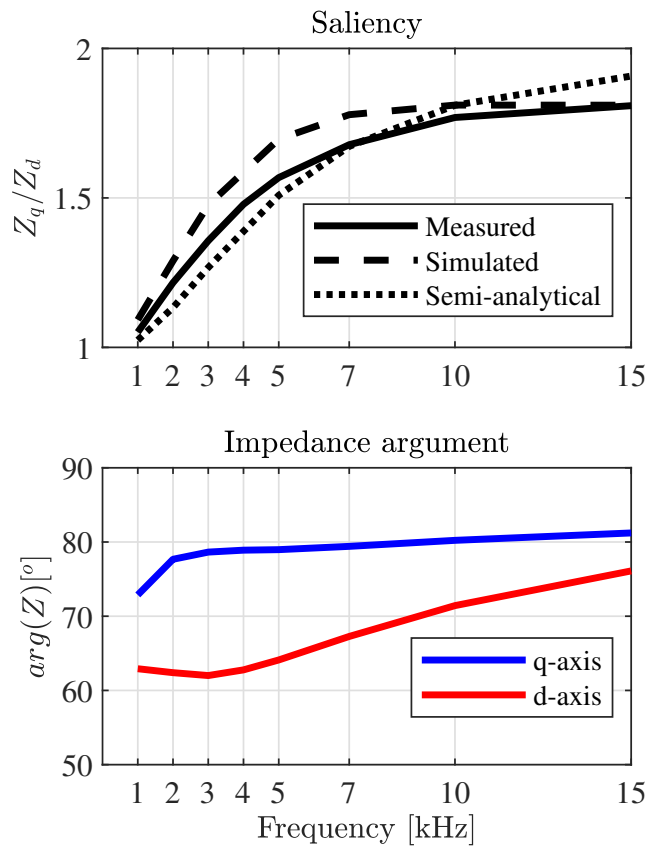

Fig. 10. Experimental evaluation using signal generator.

prototype was evaluated under $d$ and $q$-axis locked-rotor inverter supply in Fig. 11, showing a saliency of $\frac{Z_{q}}{Z_{d}}=1.45$ which is very close to the experimental results of Fig. 10. The

TABLE III INVERTER DATA

\begin{tabular}{ccc}
\hline \hline Quantity & Symbol & Value \\
\hline DC-bus voltage & $V_{\mathrm{DC}}$ & $42 \mathrm{~V}$ \\
Switching frequency & $f_{\mathrm{sw}}$ & $25 \mathrm{kHz}$ \\
Dead-time & $T_{\mathrm{d}}$ & $0.1 \mu \mathrm{s}$ \\
Signal injection frequency & $f_{\text {inj }}$ & $3125 \mathrm{~Hz}$ \\
Current sensor range & $I_{\max }$ & $\pm 70 \mathrm{~A}$ \\
\hline \hline
\end{tabular}

inverter was controlled by a dSpace 1104, deploying 3 external current sensors (LA 55-P) with $200 \mathrm{kHz}$ bandwidth and $0.65 \%$ accuracy at rated current. The prototype was assembled in a test bench and the rotor shaft was connected to an incremental encoder (Kübler 5882) with 2048 increments/revolution. The 

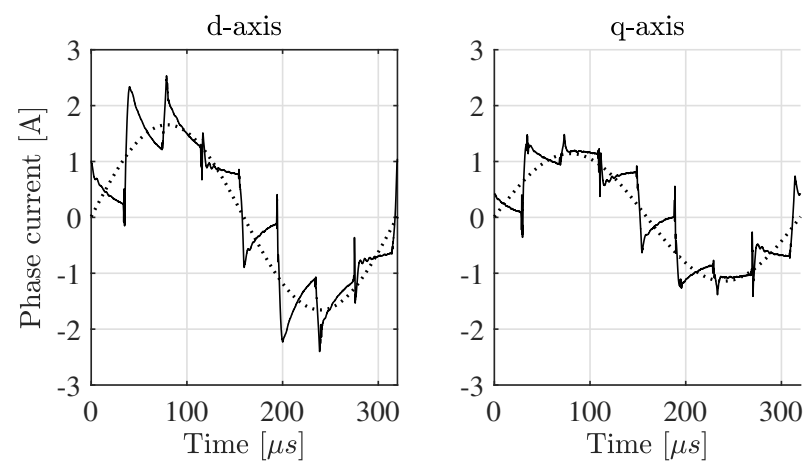

Fig. 11. Inverter locked-rotor test at $3125 \mathrm{~Hz}\left(\hat{U}_{h}=20 \mathrm{~V}\right)$.

test bench is shown in Fig. 12. The complete motor control

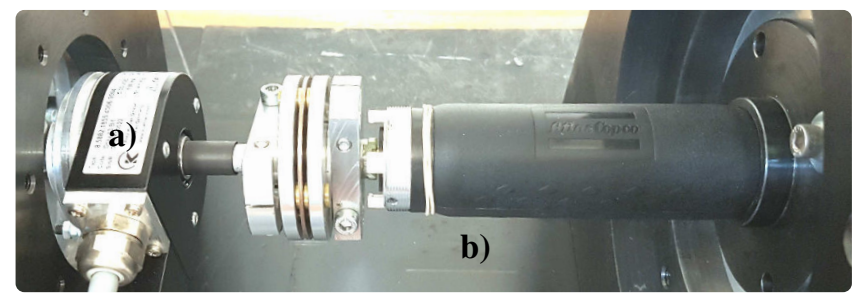

Fig. 12. The motor test-bench a) incremental encoder; b) self-sensing slotless motor.

algorithm shown in Fig. 13 is desribed in [19] and consists of a conventional cascaded PI-controller, controlling the stator currents and the rotational speed. The current and speed control loop bandwidths were set to 200 and $40 \mathrm{~Hz}$, respectively.

Rotor position estimation is achieved by injection of a highfrequency sinusoidal voltage into the stator windings according to [36]. Using the estimated rotor reference frame $d^{x}$ and $q^{x}$, the injected signals can be expressed as follows [19]:

$$
u_{h d}^{x}=\hat{U}_{h} \cos \left(\omega_{h} t\right) \quad \text { and } \quad u_{h q}^{x}=0 .
$$

The resulting high-frequency $q$-axis current is processed by the Demodulator into a DC-quantity $\left(\gamma_{\mathrm{LPF}}\right.$ in Fig. 13), containing the angular information. The rotor position and speed are finally determined by the PI-observer block (Estimator), deploying feed-forward of the $q$-axis current.

Since a small rotor movement during startup is acceptable in the application under study, the rotor is simply aligned to predetermined, DC current-vector. The injection signal frequency is preferably chosen as high as possible for achieving the highest saliency (as shown in Fig. 10), low settling time of estimation, and minimal frequency interaction between injected and fundamental signals [37]. However, the deployed hardware limits the switching frequency to $25 \mathrm{kHz}$ and subsequently the signal frequency to $3125 \mathrm{~Hz}$ that is, to 8 current samples per signal period. The signal amplitude is set to $5-10 \%$ of the nominal voltage, resulting in a signal current amplitude of about $3-7 \%$ of the rated motor current.

\section{A. Observer parameters}

Three different observer parameter setups have been evaluated (Observers A-C, see Table IV). The results are presented
TABLE IV

OBSERVER DATA

\begin{tabular}{l|c|c|c}
\hline \hline & $k_{p}$ & $k_{i}$ & $k_{f}$ \\
\hline Observer A & 5000 & 1200000 & 0 \\
Observer B & 15000 & 1200000 & 0 \\
Observer C & 15000 & 1200000 & 250000 \\
\hline \hline
\end{tabular}

in Fig. 14, where $\omega_{\text {est }}$ is the estimated speed, $\omega_{\text {ref }}$ is the reference speed and $\omega_{\mathrm{me}}$ is the measured speed from the encoder. As can be seen, Observer A exhibits fast transient speed response and short settling time. However, Observer A also gives uprise to a steady-state second harmonic speed estimation error. To overcome this issue, Observer B is proposed, unfortunately also resulting in a significantly slower transient performance. As a compromise, Observer $\mathbf{C}$ is finally proposed, utilizing feed-forward of the low-pass filtered $q$-axis current to achieve fast transient response. Observer $\mathbf{C}$ exhibits the overall best performance and is therefore used in the following sections.

\section{ESTIMATION ERROR ANALYSIS}

Even with an ideal observer, the estimation error is still aggravated by imperfections in every stage of the drive line [38][41]. The main error sources and their resulting harmonic order of distorsion are summarized in Table V. Conventional self-

TABLE V

HARMONIC IMPACT OF POSSIBLE ERROR SOURCES

\begin{tabular}{|c|c|c|c|c|}
\hline & & \multicolumn{3}{|c|}{ Hamonic order } \\
\hline & & $1^{\mathrm{st}}$ & $2^{\text {nd }}$ & $6^{\text {th }}$ \\
\hline \multirow{2}{*}{ Inverter } & \multirow{2}{*}{$\begin{array}{l}\text { Dead-time } \\
V_{\mathrm{CE}}, V_{\text {diode }}\end{array}$} & - & - & $\mathbf{x}$ \\
\hline & & - & - & $\mathbf{x}$ \\
\hline \multirow{2}{*}{ Current sensors } & \multirow{2}{*}{$\begin{array}{l}\text { DC-offset } \\
\text { Gain }\end{array}$} & $\mathbf{x}$ & - & - \\
\hline & & - & $\mathbf{x}$ & - \\
\hline \multirow{3}{*}{ Motor design } & \multirow{3}{*}{$\begin{array}{l}\text { Winding } \\
\text { Ring } \\
\text { Rotor eccentricity }\end{array}$} & - & $\mathbf{x}$ & - \\
\hline & & - & - & - \\
\hline & & - & - & - \\
\hline
\end{tabular}

sensing slotted electrical machinery suffers from an increasing estimation error with load due to saturation effects. Therefore, the influence of saturation and cross-coupling on estimation error have gained considerable attention in recent years [8], [31], [42]. However, the simulations conducted in Section II demonstrate very limited impairment of position estimation in the machine under consideration due to cross-coupling between $d$ and $q$-axis over a wide range of fundamental q-axis current (see Fig. 5), owing to its large relative air-gap. Within sensorless control of electric machinery, it is widely known that inverter non-idealities, such as dead-times, delays and voltage drops over power electronics components primarily contribute to the $6^{\text {th }}$ harmonic estimation error [37]-[40]. Fig 15 shows the influence of dead-time $T_{\mathrm{d}}$ on estimation error in the machine under investigation at $1200 \mathrm{rpm}$.

As can be seen, longer dead-time $T_{\mathrm{d}}$ significantly increases the $6^{\text {th }}$ harmonic of the estimated angle error while having negligible impact on any lower order harmonic amplitude. The results emphasize the importance of careful choice of dead-time, as well as considering implementation of adequate compensation algorithms. Unexpectedly, Fig. 15 also shows 


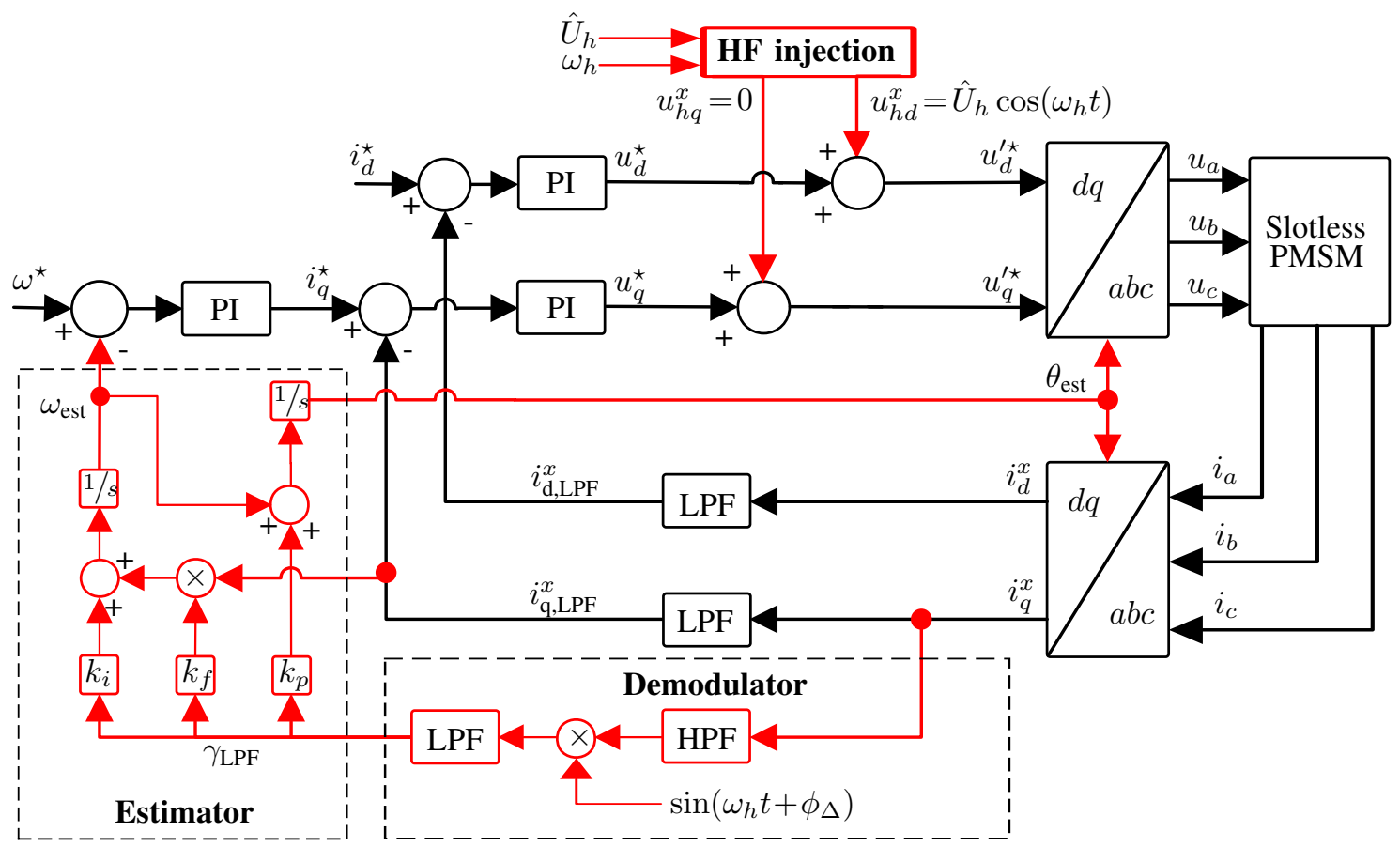

Fig. 13. Control scheme.
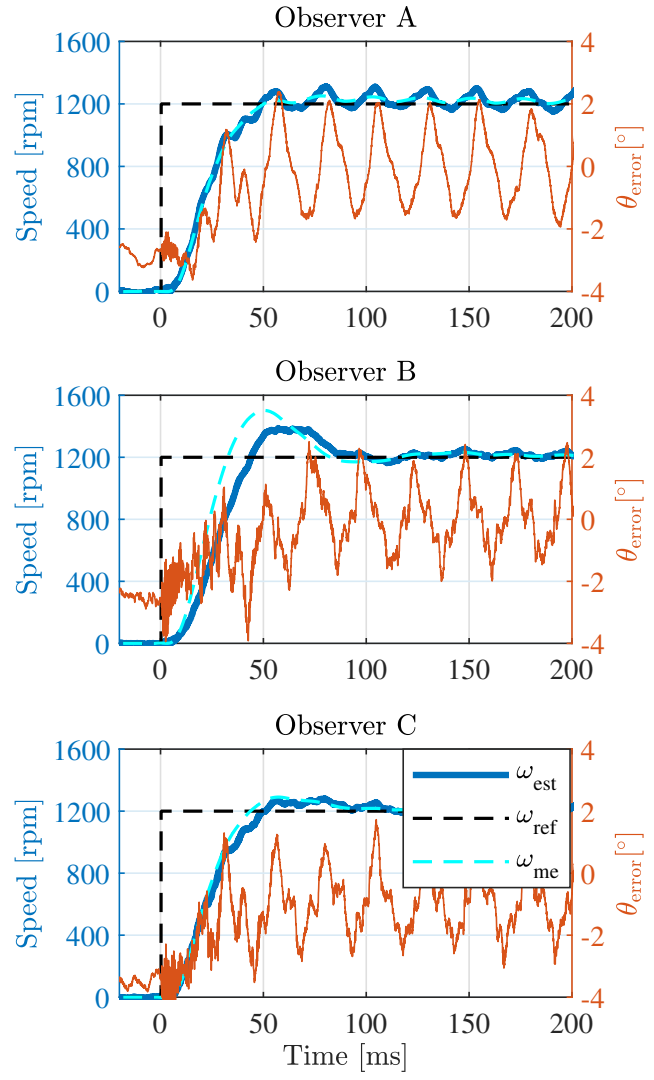

Fig. 14. Experimental results for $1200 \mathrm{rpm}$ step response using Observers $\mathrm{A}-\mathrm{C}$.

a significant second harmonic in the estimation error. It can be shown that an error in any of the current sensor offsets or gains would result in an estimation error of first and second
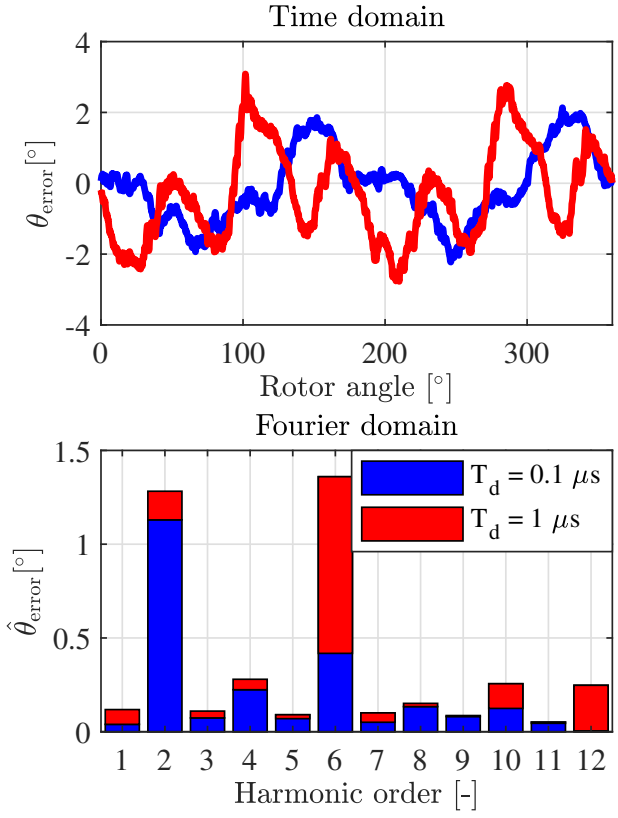

Fig. 15. Influence of dead-time $T_{\mathrm{d}}$ on estimation error at $1200 \mathrm{rpm}$ using $\hat{U}_{h}=15 \mathrm{~V}$.

order, respectively. However, analysis of the sum of currents $i_{\text {sum }}=i_{a}+i_{b}+i_{c}$ rejects both of these potential error sources (all three phase currents were measured). The influence of possible motor asymmetries due to non-ideal manufacturing have also been analyzed. The absence of stator slots in slotless machinery enables an asymmetric winding assembly, making it an important candidate for further evaluation. Another aspect that requires attention is the influence of an asymmetrically assembled rotor ring. The influence of rotor eccentricity also 
deserves attention. FEA results indicate that neither rotor eccentricity nor an asymmetrically assembled rotor ring have any influence on the second harmonic. On the contary, an asymmetrically assembled winding appears to be the only possible explanation to the second harmonic estimation error. Winding asymmetry may be efficiently compensated by using the following modification of the $a b c$ to $\alpha \beta$ transformation:

$$
T=\left[\begin{array}{lll}
\sin \left(\varphi_{a}\right) & \sin \left(\varphi_{b}-2 \pi / 3\right) & \sin \left(\varphi_{c}+2 \pi / 3\right) \\
\cos \left(\varphi_{a}\right) & \cos \left(\varphi_{b}-2 \pi / 3\right) & \cos \left(\varphi_{c}+2 \pi / 3\right)
\end{array}\right]
$$

where $\varphi_{a, b, c}$ are the displacements of phases a,b,c due to nonideal manufacturing (ideally $\varphi_{a}=\varphi_{b}=\varphi_{c}=0$ ).

\section{A. Compensation of winding asymmetry}

The influence of a promising compensation parameter setup identified by manual tuning $\left(\varphi_{a}=-1.1^{\circ} ; \varphi_{b}=0^{\circ} ; \varphi_{c}=1^{\circ}\right)$ has been evaluated in Fig. 16. The compensation reduces the second harmonic estimation error with $80 \%$ at $300 \mathrm{rpm}$.
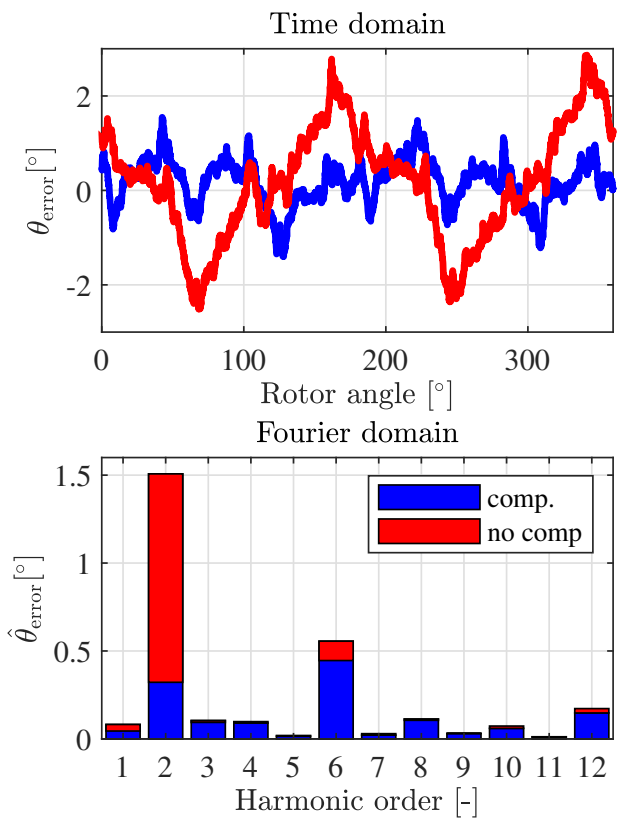

Fig. 16. Experimental results for angular estimation error at $300 \mathrm{rpm}$ using $\hat{U}_{h}=15 \mathrm{~V}$ : a) Time domain; b) Fourier domain.

\section{B. Influence of torque load}

The influence of torque load on estimation error has been evaluated at $600 \mathrm{rpm}$. Results are reported in Fig. 17, where $i_{q}=8 \mathrm{~A}$ corresponds to a high load. As can be seen, the investigated slotless machine exhibits negligible impair in position estimation at torque load (in contrast to conventional slotted electrical machinery). Moreover, the results in Fig. 17b validates the suggested compensation also under load.

\section{Influence of signal amplitude}

Using the suggested compensation, the influence of signal amplitude $\hat{U}_{h}$ on estimation error during braking (speed-step from 3000 to $0 \mathrm{rpm}$ ) has been investigated. The results are shown in Fig. 18. As can be seen, the transient estimation error during step response can be reduced by more than two thirds by increasing $\hat{U}_{h}$ from 5 to $20 \mathrm{~V}$.
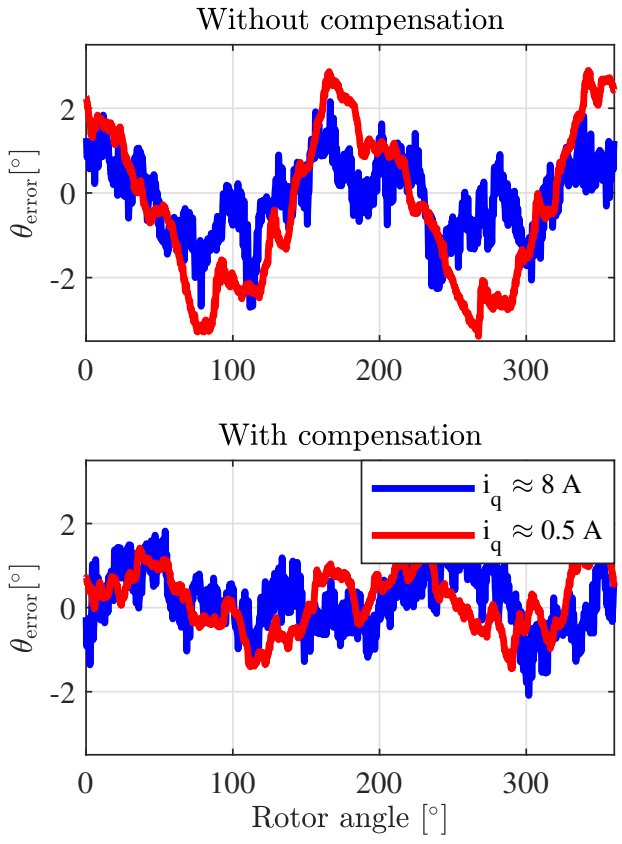

Fig. 17. Experimental results for angular estimation error during torque load at $600 \mathrm{rpm}$ for $\hat{U}_{h}=10 \mathrm{~V}$.

\section{Parasitic effects due to signal injection}

In this section, the heating and torque ripple due to signal injection are analyzed in sections VI-A and VI-B, respectively.

\section{A. Power losses and thermal evaluation}

The additional power losses due to a rotor ring can be subdivided into: a) the losses generated by the injection signal itself; b) the time-harmonic losses due to inverter switching; and c) the losses due to the space harmonics caused by the stator winding [32]. However, unlike slotted machines, the investigated slotless machine exhibits negligible levels of MMF space-harmonics [34]. Therefore, only power losses generated by the signal injection and time harmonics $(\mathrm{a}-\mathrm{b})$ are treated below.

a) Signal injection losses: The additional power losses due to signal injection have been evaluated using 2D FEA for different signal amplitude levels in the frequency range 1-15 kHz. The harmonic impedances, necessary to determine the current levels, were obtained with Eq. (3). Stator copper and rotor-ring losses have been considered, while iron losses have been neglected. The results are shown in Fig. 19. As expected, power loss minimization is not only favoured by a low signal amplitude, but also high signal frequency (due to the increasing skin-effect in the rotor ring). The stator power losses dominate until $1.5 \mathrm{kHz}$, whereafter rotor ring losses become the predominant loss source.

b) Time-harmonic losses: In this section, the additional time-harmonic motor losses due to presence of the rotor-ring are simulated for two different switching frequencies $\left(f_{\mathrm{sw}}\right)$ : 25 and $50 \mathrm{kHz}$. The typical inverter comprises a 2-level threephase inverter with a $325 \mathrm{~V}$ DC-bus, deploying symmetrical regular sampled PWM with third-harmonic injection of onesixth of the fundamental magnitude. The typical no-load time- 

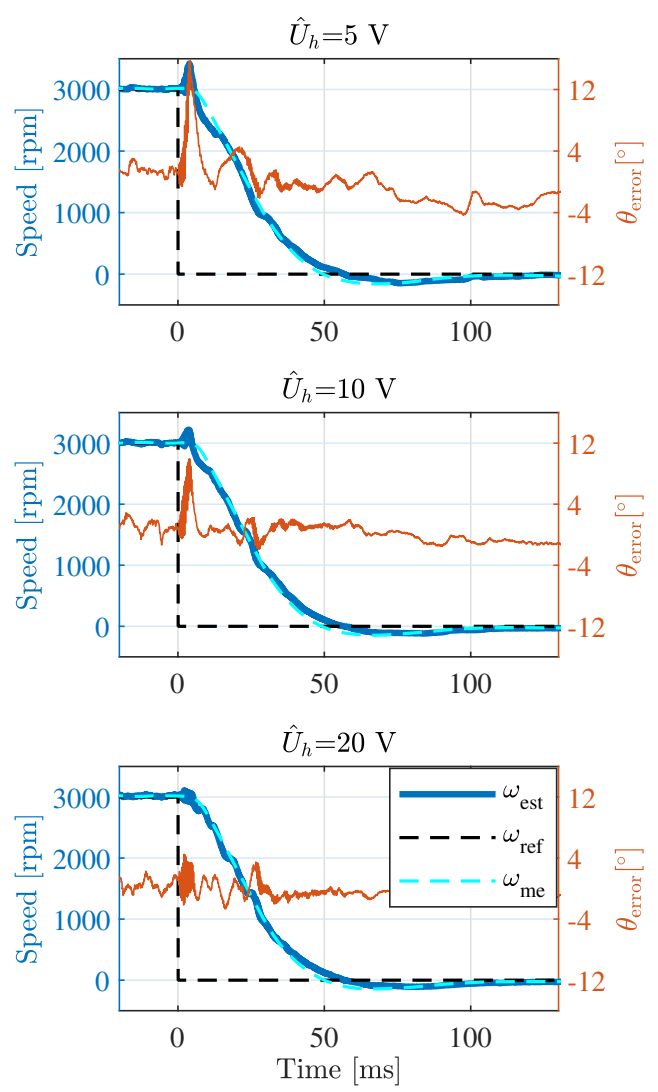

Fig. 18. Experimental results for angular estimation error during braking using different signal amplitudes.

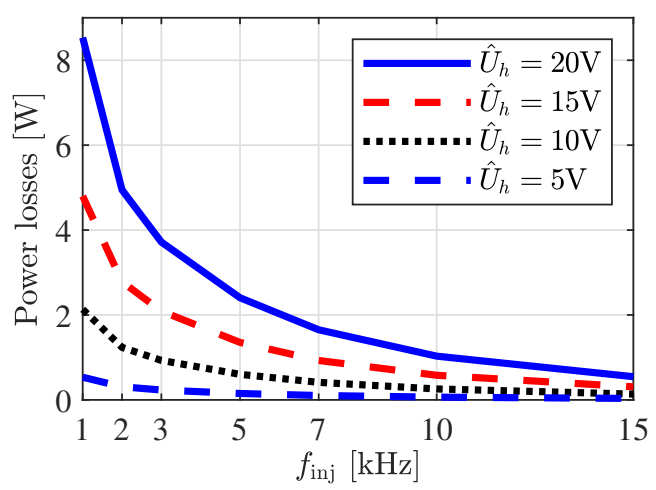

Fig. 19. Additional power losses due to signal injection from FEAsimulations.

harmonic voltage spectrum for $f_{\mathrm{sw}}=25 \mathrm{kHz}$ considering the first two harmonic sideband groups is shown in Fig. 20. The figure shows the stator reference frame $(\alpha \beta)$ as well as the rotor reference frame $(d q)$ voltage spectrum. Using [43], it can be demonstrated that the harmonic components during no-load interact to create mainly a pulsating $q$-axis voltage, subsequently creating a predominantly pulsating $d$ axis current. Utilizing Eq. (3), the current amplitudes can be approximated, and their resulting ring power losses can be evaluated using FEA. For a simplified loss analysis, the resulting rms currents of the two considered sideband groups in Fig. 20 are injected in the $d$-axis using 2D FEA at their respective multiple of switching frequency. The ring losses at $f_{\mathrm{sw}}=25 \mathrm{kHz}$ and $f_{\mathrm{sw}}=50 \mathrm{kHz}$ are estimated to $3.1 \mathrm{~W}$ and $1 \mathrm{~W}$, respectively.

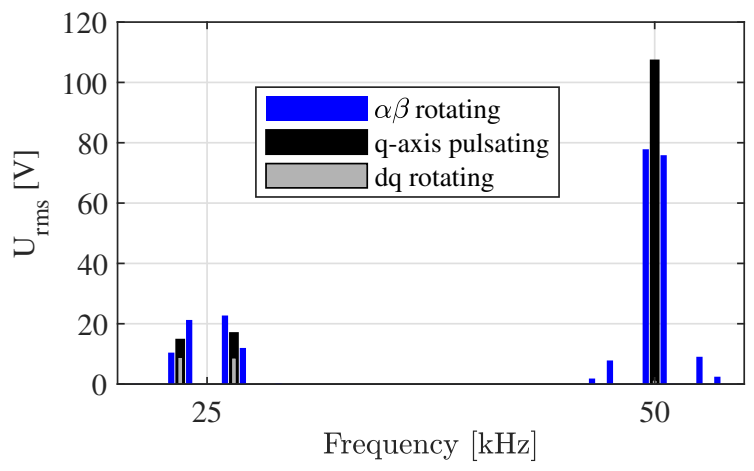

Fig. 20. Phase-to-phase voltage spectrum at $30 \mathrm{krpm}$ showing first two time-harmonic sideband groups for $25 \mathrm{kHz}$ switching frequency.

c) Thermal evaluation: Utilizing the axi-symmetric thermal model for slotless motors in [44], which takes into account temperature dependency of materials, the impact of the estimated additional ring power losses have been evaluated. The rotor-ring was represented by a $0.1 \mathrm{~mm}$ copper layer at the rotor surface, thus maintaining the same axial crosssectional ring area. The thermal impact of the time-harmonic and signal injection losses for a set of different configurations are summarized in Table VI. As can be seen, the choice of both the switching frequency and injection signal amplitude can have a significant impact on heating. However, the required experimental evaluation is out of the scope for this paper.

TABLE VI

RING HEATING CONTRIBUTION

\begin{tabular}{c|c|c|c}
$\hat{U}_{h}[\mathrm{~V}]$ & $f_{\mathrm{sw}}[\mathrm{kHz}]$ & $\Delta T$ Rotor centre & $\Delta T$ Stator surface \\
\hline 20 & 25 & $+24 \%$ & $+20 \%$ \\
10 & 25 & $+12 \%$ & $+11 \%$ \\
10 & 50 & $+4 \%$ & $+5 \%$ \\
5 & 50 & $+2 \%$ & $+3 \%$
\end{tabular}

\section{B. Torque ripple}

The output torque at rated load $\left(T_{\max }\right)$ has been simulated using time-stepping 2D FEA, assuming no estimation error. As can be seen in Table VII, the resulting torque oscillation is proportional to the signal amplitude, and in the range 0.3$1.6 \%$ of the rated torque. Even though the torque ripple is efficiently filtered out by the rotor inertia, an audible noise remains detectable.

TABLE VII

TORQUE RIPPLE

\begin{tabular}{c|c|c}
$\hat{U}_{h}[\mathrm{~V}]$ & $f_{\text {inj }}[\mathrm{Hz}]$ & Torque ripple \\
\hline 20 & 3125 & $1.6 \%$ \\
10 & 3125 & $0.8 \%$ \\
5 & 3125 & $0.4 \%$ \\
5 & 6250 & $0.3 \%$ \\
0 & - & $0.1 \%$
\end{tabular}




\section{CONCLUSION}

This paper presents a 2-pole slotless motor with self-sensing capability. Effective saliencies of up to 1.8 are demonstrated. The manufactured prototype exhibits promising speed and position estimation performance. Utilizing the suggested compensation scheme for winding asymmetry, the steady state estimation error is within $\pm 2^{\circ}$. The proposed observer also performs properly during dynamic load changes. Fall-times are demonstrated from 3000 to $0 \mathrm{rpm}$ in less than $50 \mathrm{~ms}$ with negligible overshoot. In contrast to its slotted counterparts, the investigated slotless machine exhibits negligible impair of position estimation with increased torque load. Also the ring losses and its thermal impact, as well as the torque ripple due to signal injection have been analyzed and successfully quantified. Future work includes tests at full DC-bus voltage and torque load, as well as experimental evaluation of the ring losses.

\section{REFERENCES}

[1] J. Engström, "Analysis and Verification of a Slotless Permanent Magnet Motor for High Speed Applications," PhD dissertation, KTH Royal Inst. of Technol., Stockholm, Sweden, 2001.

[2] O. Wallmark, P. Kjellqvist, and F. Meier, "Analysis of axial leakage in high-speed slotless PM motors for industrial hand tools," IEEE Trans. Ind. Appl., vol. 45, no. 5, pp. 1815-1820, 2009.

[3] N. Bianchi, S. Bolognani, and F. Luise, "High Speed Drive Using a Slotless PM Motor," IEEE Trans. Power Electron., vol. 21, no. 4, pp. 1083-1090, 2006

[4] S. G. Min and B. Sarlioglu, "Advantages and Characteristic Analysis of Slotless Rotary PM Machines in Comparison With Conventional Laminated Design Using Statistical Technique," IEEE Trans. Transp. Electrif., vol. 4, no. 2, pp. 517-524, 2018.

[5] I. Boldea, "Control Issues in Adjustable-Speed Drives - A Key Component for Realizing Energy Savings in Today's Technology," IEEE Ind. Electron. Mag., no. September, pp. 32-50, 2008.

[6] P. P. Acarnley and J. F. Watson, "Review of Position-Sensorless Operation of Brushless Permanent-Magnet Machines," IEEE Trans. Ind. Electron., vol. 53, no. 2, pp. 352-362, 2006.

[7] M. Pacas, "Sensorless Drives in Industrial Applications," IEEE Ind. Electron. Mag., vol. 5, no. 2, pp. 16-23, 2011.

[8] F. Briz and M. W. Degner, "Rotor Position Estimation," IEEE Ind. Electron. Mag., vol. 5, no. 2, pp. 24-36, 2011.

[9] A. Glumineau and J. de León Morales, Sensorless AC Electric Motor Control - Robust Advanced Design Techniques and Applications. Springer International Publishing Switzerland, 2015.

[10] N. Matsui, "Sensorless PM Brushless DC motor drives," IEEE Trans. Ind. Electron., vol. 43, no. 2, pp. 300-308, 1996.

[11] S. Bolognani, R. Oboe, and M. Zigliotto, "Sensorless Full-Digital PMSM Drive With EKF Estimation of Speed and Rotor position," IEEE Trans. Ind. Electron., vol. 46, no. 1, pp. 184-191, 1999.

[12] L. Harnefors and H. P. Nee, "A General Algorithm for Speed and Position Estimation of AC motors," IEEE Trans. Ind. Electron., vol. 47, no. 1, pp. 77-83, 2000.

[13] C. Silva, G. M. Asher, and M. Sumner, "Hybrid Rotor Position Observer for Wide Speed-Range Sensorless PM Motor Drives Including Zero Speed," IEEE Trans. Ind. Electron., vol. 53, no. 2, pp. 373-378, 2006.

[14] F. Genduso, R. Miceli, C. Rando, and G. R. Galluzzo, "Back EMF Sensorless-Control Algorithm for High-Dynamic Performance PMSM," IEEE Trans. Ind. Electron., vol. 57, no. 6, pp. 2092-2100, 2010.

[15] F. Briz, M. W. Degner, P. García, and R. D. Lorenz, "Comparison of Saliency-Based Sensorless Control Techniques for AC Machines," IEEE Trans. Ind. Appl., vol. 40, no. 4, pp. 1107-1115, 2004.

[16] J. Holtz, "Acquisition of position error and magnet polarity for sensorless control of PM synchronous machines," IEEE Trans. Ind. Appl., vol. 44, no. 4, pp. 1172-1180, 2008.

[17] I. Hahn, "Differential Magnetic Anisotropy - Prerequisite for Rotor Position Detection of PM-synchronous Machines with Signal Injection Methods," in Proc. SLED'10, IEEE Int. Symp. Sensorless Control Electr. Drives, pp. 40-49, Padova, Italy, 2010.
[18] T. D. Batzel and K. Lee, "Starting Method for Sensorless Operation of Slotless Permanent Magnet Synchronous Machines," in Proc. IEEE Power Eng. Soc. Summer Meeting, Edmonton, Canada, July 18-22, 1999.

[19] V. Manzolini, M. Morandin, and S. Bolognani, "D-axis Polarity Detection for IPM Synchronous Motor Drives by High Frequency Voltage Injection," in Proc. IEEE Ind. Electron. Conf., pp. 4325-4330, Florence, Italy, Oct. 23-26, 2016.

[20] M. Tanaskovic, C. Zhao, F. Percacci, P. Gnos, S. Mariethoz, and D. Frick, "Rotor Polarity Detection and Tracking for Slotless Permanent Magnet Synchronous Motors," in Proc. SLED'18, Helsinki, Finland, Sep. 13-14, 2018.

[21] N. Bianchi, S. Bolognani, J. H. Jang, and S. K. Sul, "Comparison of PM Motor Structures and Sensorless Control Techniques for Zero-Speed Rotor Position Detection," IEEE Trans. Power Electron., vol. 22, no. 6, pp. 2466-2475, 2007.

[22] N. Bianchi and S. Bolognani, "Influence of Rotor Geometry of an IPM Motor on Sensorless Control Feasibility," IEEE Trans. Ind. Appl., vol. 43, no. 1, pp. 87-96, 2007.

[23] R. Wrobel, A. S. Budden, D. Salt, D. Holliday, P. H. Mellor, A. Dinu, P. Sangha, and M. Holme, "Rotor Design for Sensorless Position Estimation in Permanent-Magnet Machines," IEEE Trans. Ind. Electron., vol. 58, no. 9, pp. 3815-3824, 2011.

[24] T. D. Batzel and K. Y. Lee, "Slotless Permanent Magnet Synchronous Motor Operation Without a High Resolution Rotor Angle Sensor," IEEE Trans. Energy Convers., vol. 15, no. 4, pp. 366-371, 2000.

[25] C. Zhao, M. Tanaskovic, and F. Percacci, "Sensorless Position Estimation for Slotless Surface Mounted Permanent Magnet Synchronous Motors in Full Speed Range," in SLED'17, Catania, Italy, 2017.

[26] Y. D. Yoon, S. K. Sul, S. Morimoto, and K. Ide, "High-Bandwidth Sensorless Algorithm for AC Machines Based on Square-Wave-Type Voltage Injection," IEEE Trans. Ind. Appl., vol. 47, no. 3, pp. 13611370, 2011.

[27] T. A. Nondahl, G. Ray, P. B. Schmidt, and M. L. Gasperi, "A PermanentMagnet Rotor Containing an Electrical Winding to Improve Detection of Rotor Angular Position," IEEE Trans. Ind. Appl., vol. 35, no. 4, pp. 819-824, 1999.

[28] A. Faggion, N. Bianchi, and S. Bolognani, "Ringed-Pole PermanentMagnet Synchronous Motor for Position Sensorless Drives," IEEE Trans. Ind. Appl., vol. 47, no. 4, pp. 1759-1766, 2011.

[29] J. Graus and I. Hahn, "Modelling and Optimization of a Short-Circuited Rotor Winding of a PMSM for Saliency Tracking," in Proc. SLED'14, Hiroshima, Japan, 2014.

[30] L. Alberti, N. Bianchi, M. Morandin, and S. Bolognani, "Analysis and Tests of the Sensorless Rotor Position Detection of Ringed-Pole Permanent-Magnet Motor," IEEE Trans. Ind. Appl., vol. 50, no. 5, pp. 3278-3284, 2014.

[31] D. Mingardi, M. Morandin, S. Bolognani, and N. Bianchi, "On the Proprieties of the Differential Cross-Saturation Inductance in Synchronous Machines," IEEE Trans. Ind. Appl., vol. 53, no. 2, pp. 991-1000, 2017.

[32] D. Mingardi, E. Fornasiero, N. Bianchi, S. Bolognani, and A. Faggion, "Ring Losses Evaluation in Ringed-Pole PM Motors," IEEE Trans. Ind. Appl., vol. 51, no. 5, pp. 3686-3695, 2015.

[33] K. Atallah, Z. Q. Zhu, D. Howe, and T. S. Birch, "Armature Reaction Field and Winding Inductances of Slotless Permanent-Magnet Brushless Machines," IEEE Trans. Magn, vol. 34, no. 5, pp. 3737-3744, 1998.

[34] A. G. Gonzalez, "Magnet Losses in Inverter-Fed High-speed PM Machines," Master thesis, KTH, Royal Institute of Technology, 2015.

[35] S. Ebnesajjad and A. H. Landrock, Adhesives Technology Handbook, 3rd ed. Elsevier, 2015.

[36] M. Corley and R. Lorenz, "Rotor Position and Velocity Estimation for a Salient-Pole Permanent Magnet Synchronous Machine at Standstill and High Speeds," IEEE Trans. Ind. Appl., vol. 34, no. 4, pp. 784-789, 1998.

[37] F. Gabriel, F. De Belie, X. Neyt, and P. Lataire, "High-Frequency Issues Using Rotating Voltage Injections Intended for Position Self-Sensing," IEEE Trans. Ind. Electron., vol. 60, no. 12, pp. 5447-5457, 2013.

[38] J. M. Guerrero, M. Leetmaa, F. Briz, A. Zamarrón, and R. D. Lorenz, "Inverter Nonlinearity Effects in High-Frequency Signal-Injection-Based Sensorless Control Methods," IEEE Trans. Ind. Appl., vol. 41, no. 2, pp. 618-626, 2005.

[39] C. H. Choi and J. K. Seok, "Compensation of zero-current clamping effects in high-frequency-signal-injection-based sensorless PM motor drives," IEEE Trans. Ind. Appl., vol. 43, no. 5, pp. 1258-1265, 2007.

[40] R. Raute, C. Caruana, C. S. Staines, J. Cilia, M. Sumner, and G. M. Asher, "Analysis and Compensation of Inverter Nonlinearity Effect on a Sensorless PMSM Drive at Very Low and Zero Speed Operation," IEEE Trans. Ind. Electron., vol. 57, no. 12, pp. 4065-4074, 2010. 


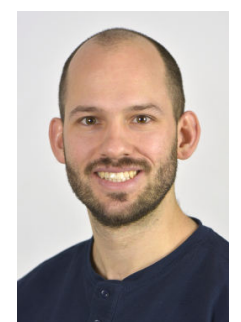

Jonas Millinger ( $\left.S^{\prime} 16\right)$, born in Stockholm, Sweden received the M.Sc. degree in electrical engineering from the KTH Royal Institute of Technology, Stockholm, Sweden, in 2011, where he is currently working toward the Ph.D. degree with the Department of Electric Power and Energy Systems. Since 2010, he has been with Atlas Copco, Stockholm, where he is involved in the design of electrical machines for power tools. His research interests include modeling and design of electrical machines, with a current focus on harmonic losses and motordrive system optimization.

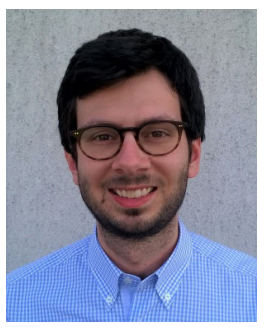

Giacomo Bacco (S'17) received both the BS in Energy Engineering in 2013 and the MS in Electrical Engineering in 2016 from the University of Padova, Padova, Italy. Currently he is a PhD student of the Department of Industrial Engineering at the same university. His research interests are focused in the analysis and design of synchronous machines, in particular synchronous reluctance (REL) motors.

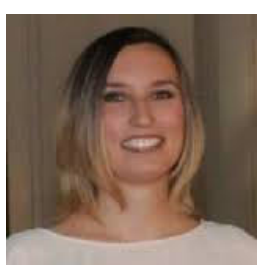

Virginia Manzolini (S'16) received the B.S. degree in Information Engineering and the M.S. degree in Automation Engineering from University of Padova in 2013 and 2015 respectively. She is currently working toward the Ph.D. degree at the same University. Her main research activity deals with innovative control strategies for electrical AC drives, with particular focus to field-weakenig and sensorless control of Synchronous Reluctance Machines.

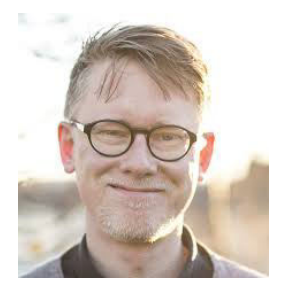

Oskar Wallmark (S'01-M'06-SM'18), born in 1976, Sweden, received his M.Sc. in Engineering Physics in 2001 and his Ph.D. in Electric Power Engineering in 2006, both from Chalmers University of Technology, Göteborg, Sweden. In 2015, he received the Docent degree from KTH Royal Institute of Technology. Currently, he holds the position as an Associate Professor at the Department of Electric Power and Energy Systems. His main research interests include control and automotive applications.
[41] T. M. Wolbank, M. A. Vogelsberger, and M. Riepler, "Identification and Compensation of Inverter Dead-Time Effect on Zero Speed Sensorless Control of AC Machines Based on Voltage Pulse Injection," in Proc. IEEE Power Electron. Spec. Conf., pp. 2844-2849, Rhodes, Greece, June 15-19, 2008.

[42] M. Barcaro, M. Morandin, T. Pradella, N. Bianchi, and I. Furlan, "Iron Saturation Impact on High Frequency Sensorless Control of Synchronous Permanent Magnets Motor," IEEE Trans. Ind. Appl., vol. 53, no. 6 , pp. 5470-5478, 2017.

[43] T. Lipo and D. G. Holmes, Pulse Width Modulation for Power Converters, 1st ed. Wiley-IEEE Press, 2003.

[44] J. Millinger, O. Wallmark, and J. Soulard, "Thermal Modeling of Slotless PM Motor for Industrial Hand Tools," in Proc. IEEE Int. Conf. Electrical Machines, pp. 2695-2701, Alexandroupolis, Greece, Sep. 3-6, 2018.

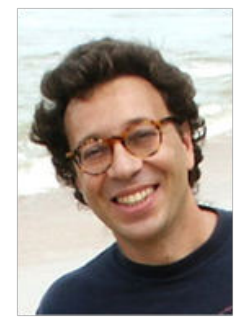

Nicola Bianchi (M'98-SM'0-F'14), received the M.Sc. and Ph.D. degrees in electrical engineering from the University of Padova, Padova, Italy, in 1991 and 1995, respectively. In 1998, he joined the Department of Electrical Engineering, University of Padova, as an Assistant Professor, where since 2005, he has been an Associate Professor in electrical machines, converters, and drives with the Electric Drive Laboratory, Department of Electrical Engineering. He is the author or coauthor of several scientific papers and international books on electrical machines and drives. His research interests include the field of design of electrical machines, particularly for drive applications, in which he is responsible for various projects for local and foreign industries. Dr. Bianchi is the recipient of five awards for best conference and journal papers. He is a member of the Electric Machines Committee and the Electrical Drives Committee of the IEEE Industry Applications Society. He was a Technical Program Chair for the IEEE Energy Conversion Congress and Exposition 2014 and is currently an Associate Editor for the IEEE TRANSACTIONS ON INDUSTRY APPLICATIONS. 